\title{
Indigenas residentes em domicílios "improvisados" segundo o Censo Demográfico 2010
}

| ${ }^{1}$ Gerson L. Marinho, ${ }^{2}$ Aline Diniz Rodrigues Caldas, ${ }^{3}$ Ricardo Ventura Santos I

Resumo: Os censos nacionais brasileiros empregam uma classificação de domicílios que se baseia nas categorias de "permanente", "improvisado" e "coletivo". Tal categorização é relevante para o campo da saúde, pois informações detalhadas sobre saneamento são coletadas somente para domicílios classificados como "permanentes". Este estudo descreve características sociodemográficas dos indígenas (sexo, idade, alfabetização, rendimento e etnia) que residiam em domicílios "improvisados" segundo o Censo Demográfico de 2010. A ocorrência de indígenas em domicílios “improvisados" (3,3 por mil indígenas) foi o dobro daquela observada para o país como um todo (1,5 por mil pessoas). Comparados aos indígenas em domicílios "permanentes”, aqueles em "improvisados" apresentaram menores proporções de pessoas alfabetizadas e menores rendimentos, sobretudo em áreas urbanas e fora de terras indígenas. Guarani Kaiowá e Kaingang residentes fora de terras indígenas apresentaram as mais expressivas ocorrências de residentes em domicílios “improvisados" (82,0 e 90,9 por mil, respectivamente). Argumenta-se que, ao mesmo tempo que a caracterização de uma moradia indígena como "improvisada" pode decorrer de problemas na definição e aplicação das categorias, é possível que, sobretudo no contexto urbano e fora de terras indígenas, os indígenas residentes em domicílios "improvisados" apresentem maior vulnerabilidade socioeconômica.

> Palavras-chave: população indígena; censo demográfico; iniquidade social.

\author{
1 Escola de Enfermagem Anna \\ Nery, Universidade Federal do \\ Rio de Janeiro. Rio de Janeiro-RJ, \\ Brasil (marinho@eean.ufrj.br). \\ 2 Seção de Auditoria do Sistema \\ Único de Saúde, Núcleo \\ Estadual do Rio de Janeiro, \\ Ministério da Saúde.. Rio de \\ Janeiro-RJ, Brasil (alinediniz. \\ caldas@gmail.com). \\ ${ }^{3}$ Escola Nacional de Saúde \\ Pública Sergio Arouca, \\ Fundação Oswaldo Cruz. Rio de \\ Janeiro-RJ, Brasil (santos@ensp. \\ fiocruz.br).
}

Recebido em: 05/11/2015 Aprovado em: 02/08/2016 


\section{Introdução}

Os censos nacionais são importantes fontes para o conhecimento dos perfis demográficos, econômicos e sociais das populaçōes (UN, 2008; 2009). A quantificação de características de indivíduos e domicílios em recenseamentos produz informações que são amplamente utilizadas no delineamento e implementação de políticas públicas nas áreas de educação, saúde, saneamento, moradia, entre outras (BERCOVICH; PEREIRA, 1999; ALVES; CAVENAGHI, 2004; BOOTH, 2010; UN, 2008).

No Brasil, censos nacionais têm sido realizados desde a segunda metade do século XIX, passando a ter periodicidade decenal em meados do século XX. Uma tendência que se observa nos levantamentos censitários recentes na América Latina é a inclusão, ou mesmo expansão, de quesitos referentes à composição étnico-racial (DEL POPOLO, 2008; LOVEMAN, 2014). O caso brasileiro é bastante ilustrativo dessa tendência. Assim, desde os anos 1940 vêm sendo coletadas informações sobre "cor ou raça" da população utilizando-se basicamente a mesma classificação (branca, preta, amarela e parda), tendo sido incluída a categoria "indígena" a partir do censo realizado em 1991 (PAGLIARO; AZEVEDO; SANTOS, 2005; IBGE, 2005).

No caso dos levantamentos censitários no Brasil, os domicílios são classificados pelo Instituto Brasileiro de Geografia e Estatística (IBGE) como "particular" ou "coletivo" (IBGE, 2013). São considerados particulares "aqueles em que o relacionamento entre seus ocupantes seja ditado por laços de parentesco, de dependência doméstica e por normas de convivência". Por sua vez, os "coletivos" incluem hotéis, pensões, orfanatos, quartéis, entre outros (IBGE, 2013, p. 310). Os "particulares" se subdividem em "permanentes" ("construídos para servir exclusivamente à habitação com finalidade de moradia a uma ou mais pessoas") e "improvisados" ("que não serviam exclusivamente como moradia, mas que na data da entrevista do censo, serviam para tal”) (ALVES; CAVENAGHI, 2004; IBGE, 2012). Prédios em construção, vagóes de trens, carroças, tendas, barracos são exemplos de domicílios "improvisados" (IBGE, 2013, p. 310). O questionário básico do Censo 2010 incluiu 37 perguntas, sendo que para os domicílios "particulares improvisados" e "coletivos" não foram coletadas variáveis relacionadas a saneamento (formas de abastecimento de água, existência de banheiro, destino de dejetos e lixo doméstico e disponibilidade de energia elétrica) (IBGE, 2013). 
Uma significativa inovação do Censo 2010 foi a investigação do pertencimento

étnico específico e línguas faladas para pessoas que se declararam "indígenas" (IBGE, 2012). Desse modo, as informaçōes produzidas por esse censo se tornaram relevantes para o conhecimento da sociodiversidade indígena no país (AZEVEDO, 2011; FUNAI/IBGE, 2011; OLIVEIRA, 2012; SANTOS; TEIXEIRA, 2011). Embora os 817,9 mil indígenas contabilizados em 2010 representassem menos de $0,5 \%$ da população brasileira, foram identificadas mais de 300 etnias e aproximadamente 180 línguas (SANTOS; TEIXEIRA, 2011; IBGE, 2012). No contexto latino-americano, o Brasil é um dos países que apresenta a maior diversidade de etnias indígenas (MONTENEGRO; STEPHENS, 2006).

Conforme apontado em diversas análises sociodemográficas, há significativos desafios envolvidos na caracterização de minorias étnicas a partir de dados censitários (KERTZER; AREL, 2002; DEL POPOLO, 2008; PAGLIARO; AZEVEDO; SANTOS, 2005; UN, 2008). Por se constituírem em segmentos socioculturalmente diferenciados, os indígenas podem apresentar padrōes de moradia que venham a ser percebidos como "improvisados" ou "provisórios" pelos recenseadores, mas que fazem parte de modos tradicionais de habitação (NOVAES, 1983; GALLOIS, 2004). Ao mesmo tempo, não se pode deixar de considerar situações nas quais, decorrentes de invasão de suas terras, fragilização das atividades econômicas, mudanças em busca de trabalho e educação, entre outros fatores, haja deslocamento de indígenas para outros contextos rurais e urbanos, e que a eles se associem padrôes de habitação precarizados do ponto de vista socioeconômico e sanitário.

Nesse complexo cenário, é de fundamental importância exercitar uma perspectiva crítica acerca das categorias de classificação utilizadas nos recenseamentos oficiais, uma vez que são amplamente empregadas em análises no campo da Saúde Coletiva. Isso porque as condições de saúde se vinculam proximamente com as características dos domicílios, o que tem sido referido em análises sobre habitações indígenas (e não indígenas) em diversas partes do mundo (STEPHENS et al., 2006; KING; SMITH; GRACEY, 2009; PHIBBS; THOMPSON, 2011; BAILIE; STEVENS; MacDONALDS, 2012).

O objetivo deste artigo é investigar as características sociodemográficas de indígenas que residiam em domicílios classificados como "particulares 
improvisados" a partir do Censo 2010, com foco em sexo, idade, alfabetização, renda per capita e etnia. As estratificações envolvem a localização do domicílio (área urbana ou rural) e se em terra indígena ou não. As análises são pautadas por uma perspectiva crítica acerca do uso de categorias censitárias para um segmento da população socioculturalmente diferenciado.

\section{População e Métodos}

A fonte de dados foi o "Universo" do Censo 2010, ou seja, aqueles derivados do chamado "Questionário Básico", obtidos através do Banco Multidimensional de Estatísticas (BME) (http://www.bme.ibge.gov.br, acessado em 31 de maio de 2015).

Foram calculadas, inicialmente, as taxas de residentes em domicílios particulares improvisados segundo categorias de cor ou raça (branca, preta, amarela, parda e indígena) e situação dos domicílios (urbana e rural). Também foram descritas as taxas de domicílios improvisados considerando a cor ou raça da pessoa responsável.

Características individuais (sexo, idade, alfabetização, rendimento mediano per capita e etnia) foram obtidas para indígenas em domicílios particulares permanentes eimprovisados localizados em áreas urbanas erurais. Adicionalmente, para alfabetização e rendimento, apresenta-se estratificação segundo localização dentro e fora de terras indígenas. Para fins da coleta censitária, "o conjunto de terras indígenas foi formado por aquelas que estavam na situação fundiária de declarada, homologada, e em processo de aquisição como reserva indígena até a data de 31 de dezembro de 2010" (IBGE, 2012, p. 16).

No Censo 2010, foi considerada alfabetizada a pessoa maior de cinco anos de idade "capaz de ler e escrever pelo menos um bilhete simples no idioma que conhece" (IBGE, 2012, p. 41). O rendimento nominal mensal per capita se refere ao "total declarado pelos moradores em salários-mínimos, excetuando pensionistas e empregados domésticos" (IBGE, 2012, p. 47).

Foram analisadas as distribuições de indígenas residentes em domicílios improvisados urbanos e rurais nas Unidades da Federação (UF) das cinco regiōes do país, assim como dentro e fora de terras indígenas. Com foco nas três UFs que apresentaram as maiores frequências absolutas de indígenas residentes em 
domicílios improvisados (Amazonas - AM, Mato Grosso do Sul - MS e Rio Grande do Sul - RS), investigou-se a ocorrência naquelas etnias com pelo menos mil pessoas residentes nos domićlíios localizados dentro e fora de TI.

Decorrente dos critérios de confidencialidade na divulgação dos dados censitários, valores de variáveis com frequências maiores que zero (0) e menores que seis (6) não são especificamente indicados nas tabulações geradas no BME, sendo apresentados como " $x$ ". Nessas situaçōes, assumiu-se o valor três (3) por ser o intermediário no conjunto dos registros omitidos (1, 2, 3, 4 ou 5).

Cabem alguns esclarecimentos acerca de terminologias empregadas neste estudo. Os termos são aqueles utilizados pelo IBGE na documentação sobre o Censo 2010, a exemplo da localização dos domicílios em áreas urbanas e rurais, denominada "situação de domicílio" (IBGE, 2013). Expressões referentes à classificação dos domićlios (particular permanente, particular improvisado e coletivo), assim como "responsável pelo domicílio", não são necessariamente as que julgaríamos mais apropriadas para descrever os contextos indígenas, mas são aqui empregadas pois fazem parte da terminologia censitária.

\section{Resultados}

Para o país como um todo, o Censo 2010 contabilizou 2.724 indígenas residentes em domicílios classificados como particulares improvisados, correspondendo a 0,4\% do total de indígenas no país (817,9 mil) e a uma taxa de 3,3 por mil (tabela 1). Havia duas vezes mais indígenas residindo em domicílios improvisados se comparados à população brasileira em geral (1,5 por mil), sendo também a maior ocorrência entre as categorias de cor ou raça.

Na situação urbana, a taxa de moradores indígenas em domicílios improvisados (3,9 por mil) foi aproximadamente o triplo daquela registrada para pretos (1,4 por mil), alcançando cinco vezes a observada para brancos ( 0,7 por mil), segundo a tabela 1. Por outro lado, na situação rural, a taxa para indígenas foi uma das mais baixas (3,0 por mil), semelhante a de brancos. Em relação à cor ou raça da pessoa responsável, o padrão se mostrou similar ao descrito para moradores. 


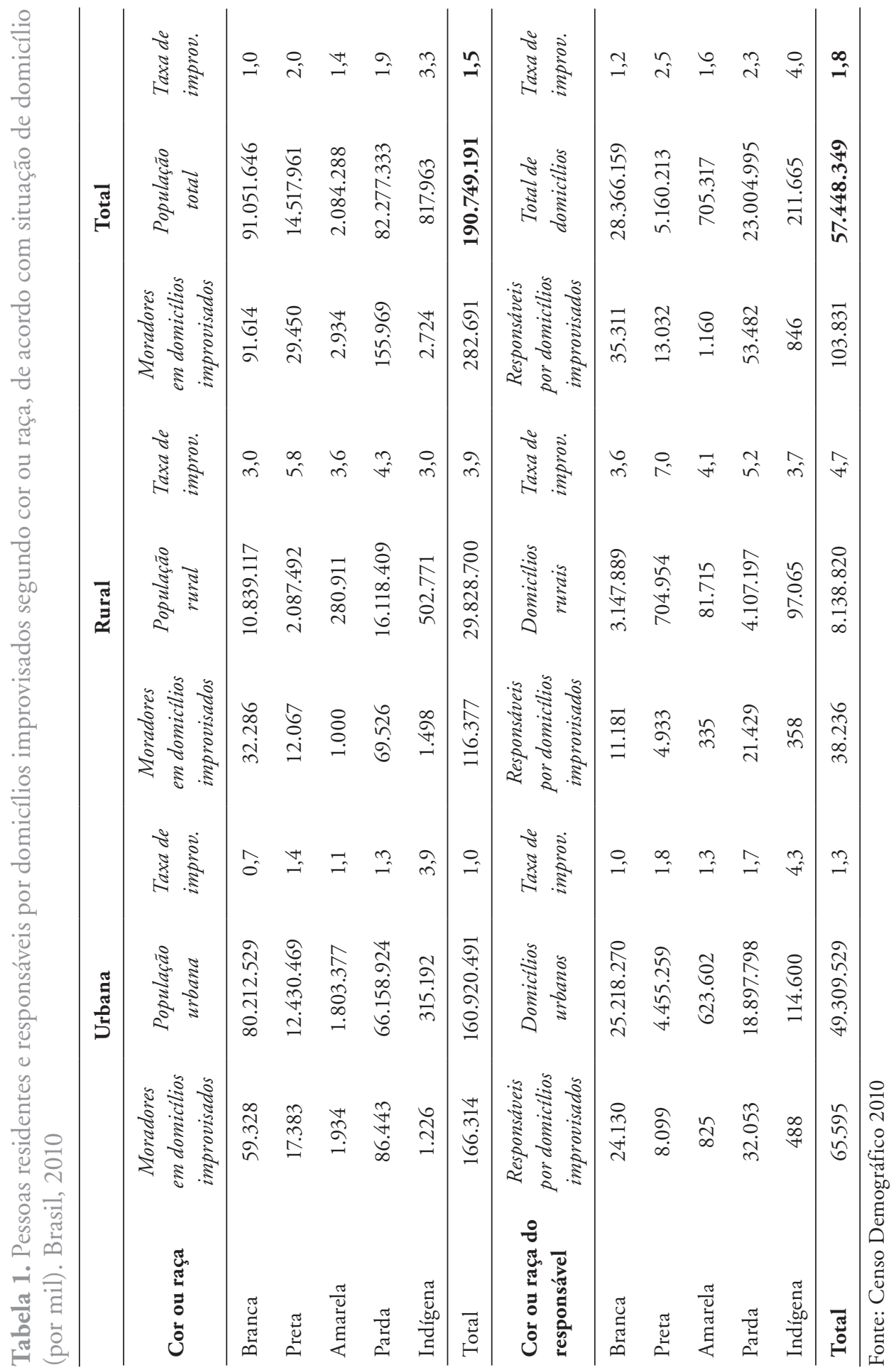


Enquanto indígenas em domicílios improvisados e permanentes residentes na situação urbana apresentaram estrutura populacional mais envelhecida, não foram observadas diferenças no tocante à composição por sexo segundo situação de residência (figura 1).

Figura 1. Pirâmides etárias de indígenas residentes em domicílios improvisados (1.a e 1.b) e permanentes (1.c e 1.d) em situação urbana e rural, respectivamente. Brasil, 2010
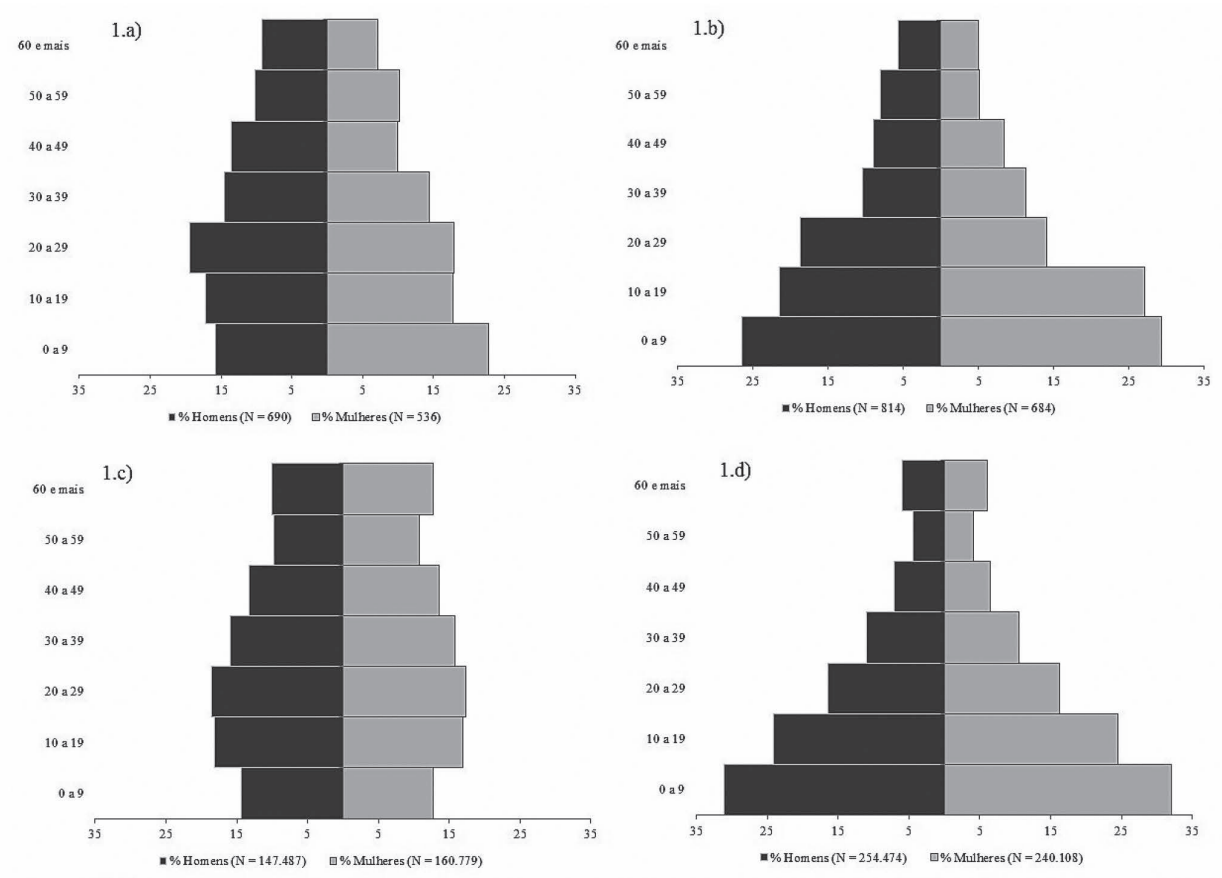

Fonte: Censo Demográfico 2010.

A proporção de indígenas não alfabetizados residentes em domicílios improvisados (27,5\%) localizados em áreas urbanas foi duas vezes superior àquela verificada em indígenas de domicílios permanentes (12,9\%), conforme a tabela 2. $\mathrm{Na}$ situação rural, os valores foram menos discrepantes (34,4\% vs. 35,6\%). Quanto a rendimento, se na situação rural os valores medianos per capita se mostraram próximos ( $\mathrm{R} \$ 66,67$ vs. $\mathrm{R}$ \$ 50,00), na urbana os indígenas residentes em domicílios improvisados apresentaram valores expressivamente mais baixos que aqueles de moradores em domicílios permanentes $(\mathrm{R} \$ 133,33$ vs. $\mathrm{R} \$ 265,00)$ (tabela 2). 


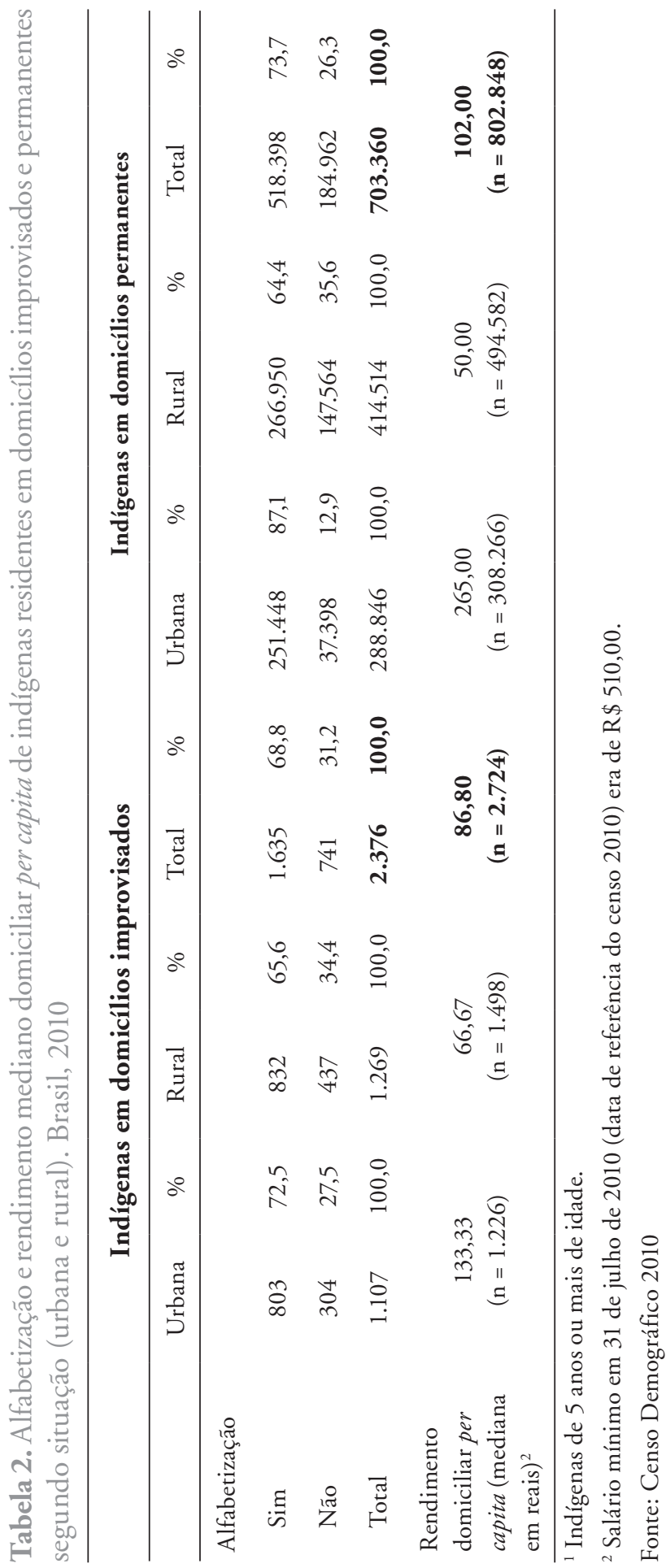


Para os domicílios improvisados localizados fora de TI, a proporção de indígenas não alfabetizados foi o dobro daquela observada para os residentes em domicílios permanentes $(30,8 \%$ vs. $16,1 \%)$, de acordo com a tabela 3. Para os situados em TI, as diferenças se mostraram pouco expressivas (32,5\% vs. 36,0\%). Fora de TI, o rendimento mediano dos indígenas em domicílios permanentes foi o dobro do registrado para os que residiam em domicílios improvisados ( $\mathrm{R} \$$ 233,33 vs. $\mathrm{R} \$ 100,00$ ) (tabela 3). Chama atenção que, em TI, ainda que os valores sejam bastante baixos, os residentes em domicílios improvisados apresentaram rendimento mediano ligeiramente mais elevado que os moradores de domicílios permanentes ( $\mathrm{R} \$ 65,60$ vs. $\mathrm{R} \$ 45,33)$.

Em termos absolutos, as maiores frequências de indígenas em domicílios improvisados foram registradas nas regiōes Norte e Sul (679 e 728, respectivamente). Apenas no Sul (9,7 por mil) e Centro-Oeste (3,8 por mil), as taxas superaram aquela observada para o país como um todo (3,3 por mil) (tabela 4). Foi também no Sul onde se verificaram as mais elevadas taxas segundo situação urbana e rural (9,9 e 9,6 por mil, respectivamente).

Quanto à distribuição nas Unidades da Federação, as mais elevadas proporções de indígenas em domicílios improvisados foram observadas no Rio Grande do Sul - RS (15,0\% do total no país), Mato Grosso do Sul - MS $(14,5 \%)$ e Amazonas - AM (13,6\%) (tabela 4). Na situação rural, essas três UFs também apresentaram as mais elevadas frequências (13,7\%, 15,3\% e 18,6\%, respectivamente). RS e MS se destacaram pelas maiores ocorrências na situação urbana (16,4\% e $13,4 \%$, respectivamente).

Todas as UFs da Região Sul (Paraná, Santa Catarina e Rio Grande do Sul) apresentaram taxas de indígenas em domicílios improvisados superiores a 5,0 por mil, alcançando 12,3 por mil no RS. Na situação urbana, foram observadas taxas superiores a 10,0 por mil no Acre (18,9), Rio Grande do Sul $(14,5)$ e Mato Grosso do Sul $(11,3)$. Na rural, as três UFs da Região Sul também se destacaram por apresentarem taxas mais elevadas. Ainda na situação rural, as taxas registradas para Piauí, Rio de Janeiro e Goiás também foram expressivas, mas é possível que estejam relacionadas ao reduzido número de indígenas em improvisados (15, 9 e 9, respectivamente), bem como ao total de indígenas (587, 738 e 514, respectivamente), como mostra a tabela 4 . 


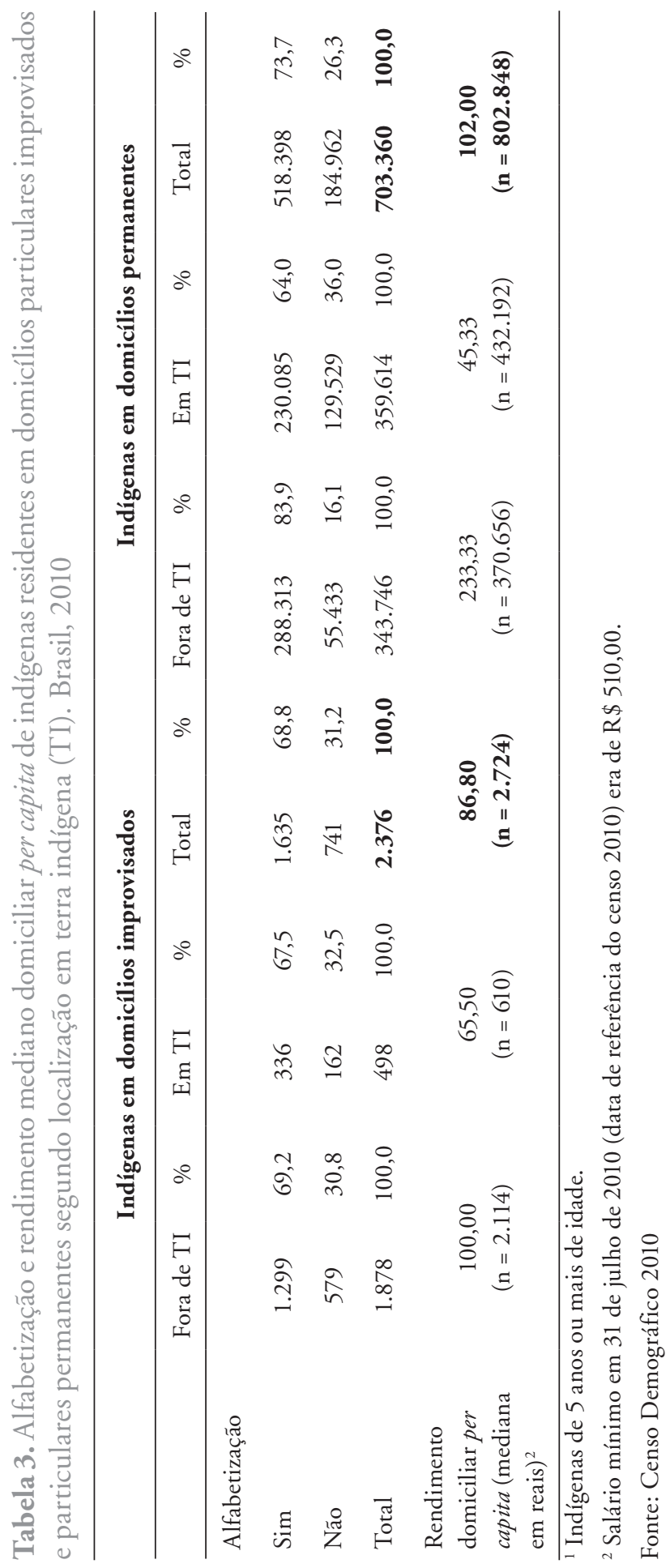









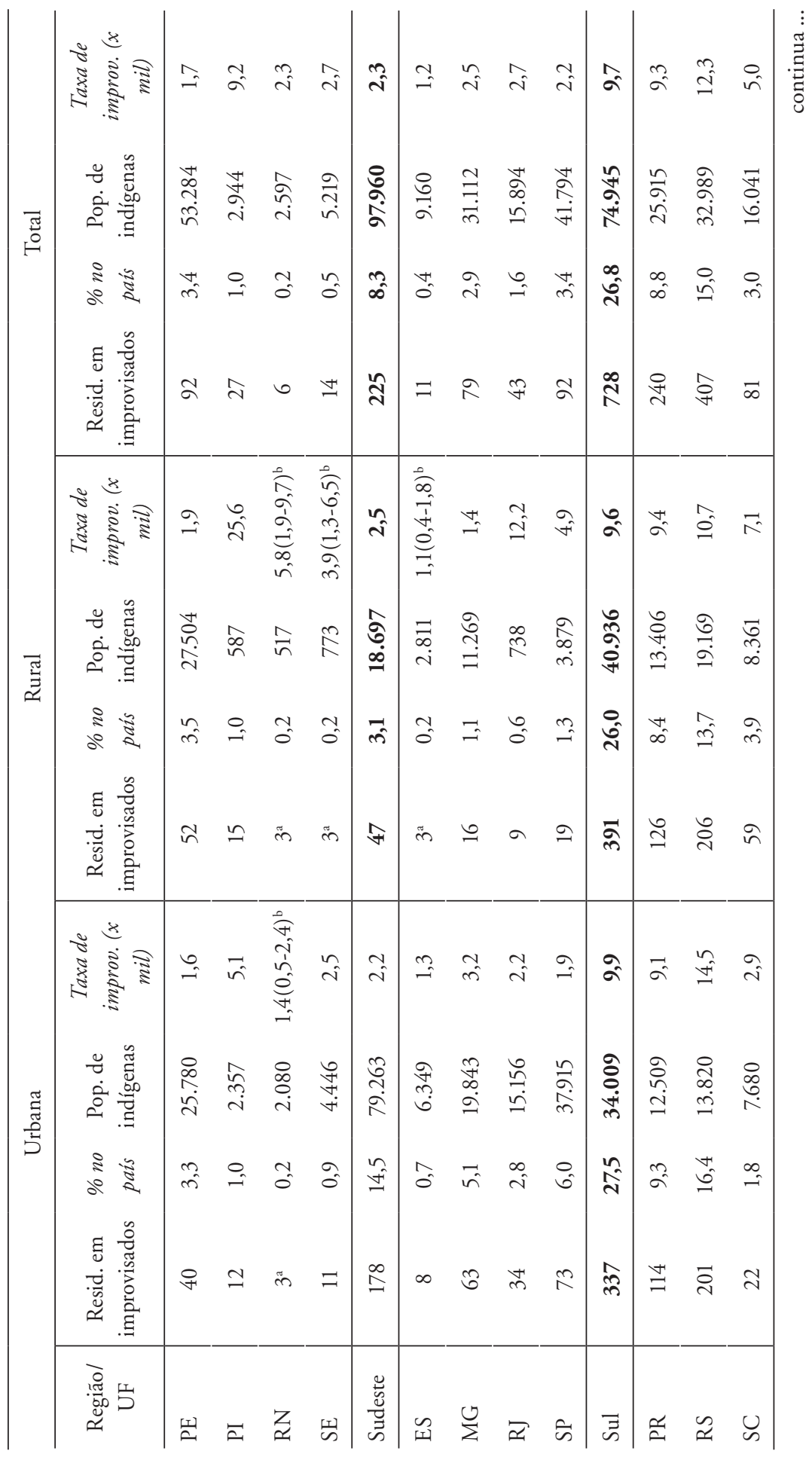




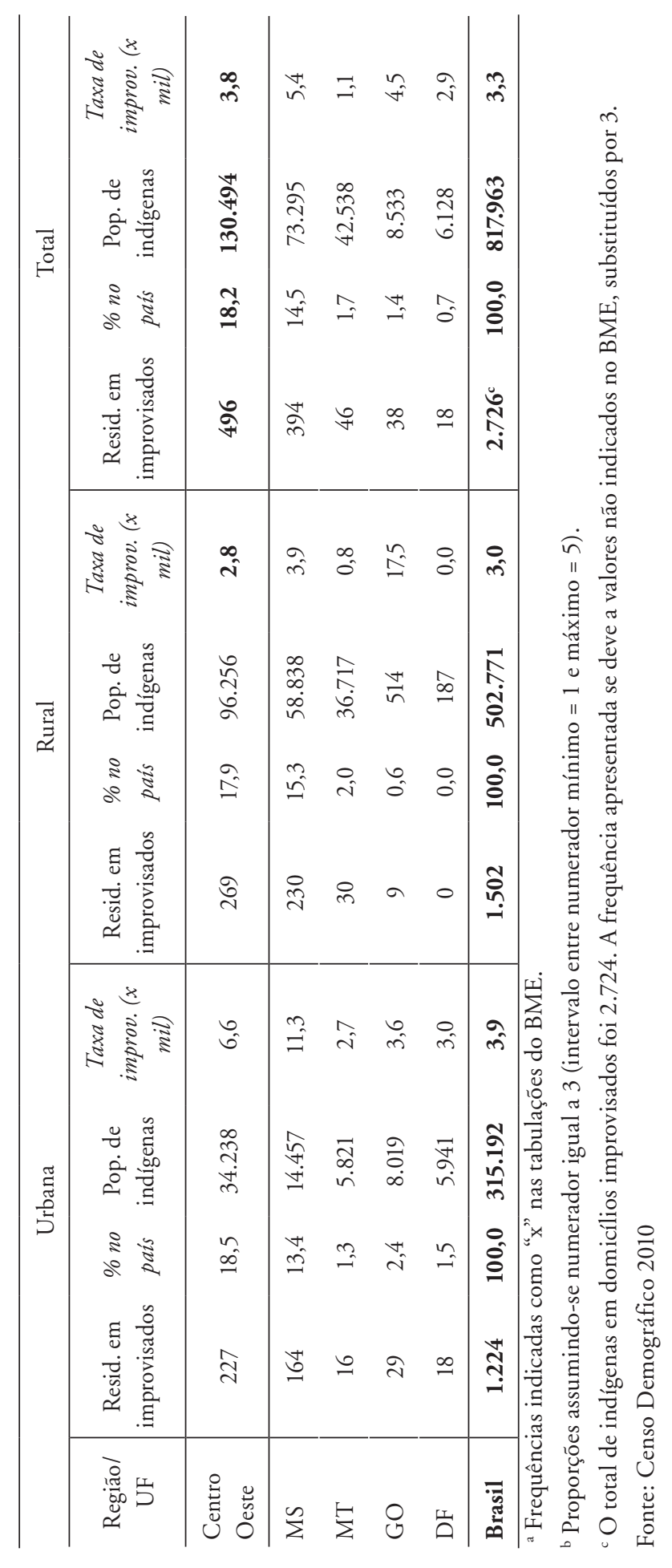


Valores não especificamente indicados nas tabulações do BME/IBGE ocorreram na situação urbana de Tocantins e Rio Grande do Norte, e na rural do Amapá, Rondônia, Paraíba, Rio Grande do Norte, Sergipe e Espírito Santo (tabela 4). Em todos esses casos, os totais de indígenas (denominadores das taxas) foram superiores a 500, de modo que os intervalos das taxas de residentes em domicílios improvisados (mínimo e máximo possíveis) se mostraram reduzidos, pouco impactando nas análises comparativas segundo UF.

Figura 2. Indígenas em domicílios improvisados de acordo com localização do domicílio em terras indígenas (por mil), segundo Unidades da Federação. Brasil, 2010.

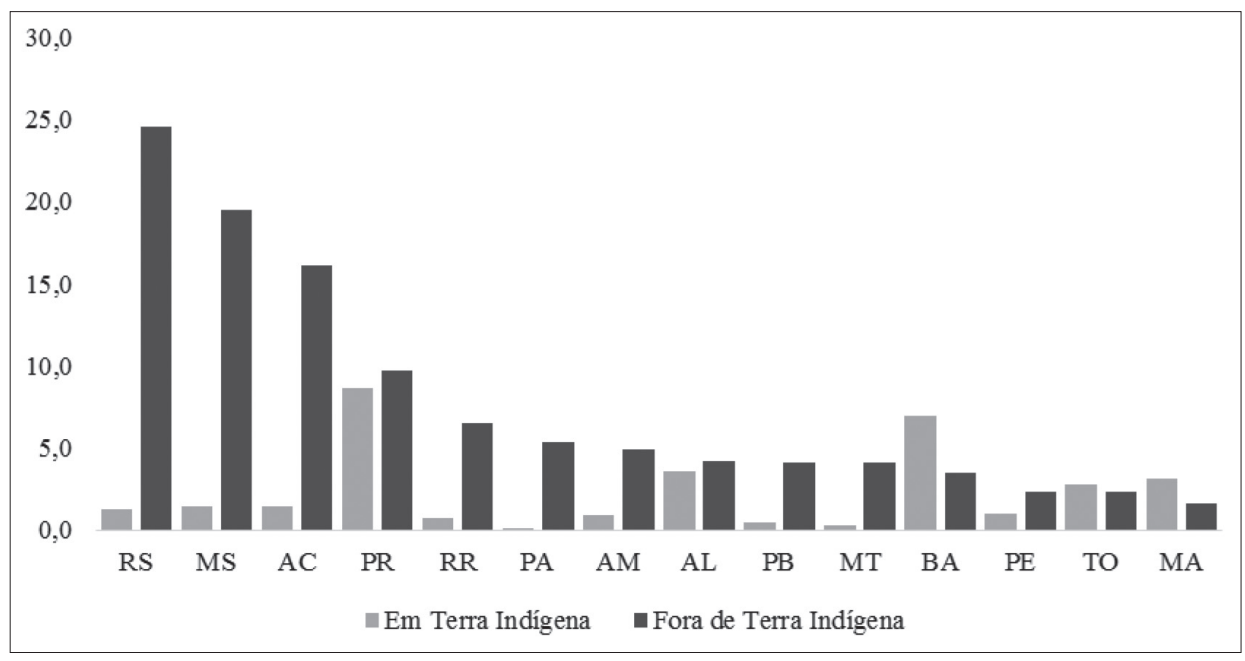

Fonte: Censo Demográfico 2010.

Dos 438,4 mil indígenas residentes em terras indígenas (53,6\% do total no país), 1,4 por mil moravam em domicílios improvisados. Em contraste, fora de TI, foi observada uma taxa de 5,6 por mil. Dentre as 24 UF com TI, em 14 havia indígenas em domicílios improvisados localizados em TI (Figura 2). A UF com maior taxa de moradores indígenas em TI foi o Paraná (8,7 por mil). Fora de TI, as mais expressivas taxas ocorreram no Rio Grande do Sul, Mato Grosso do Sul e Acre (24,5; 19,5 e 16,2 por mil, respectivamente), superando em pelo menos dez vezes os valores observados para indígenas residentes nas TI destas UF. Na Bahia foi registrada uma taxa expressivamente maior em TI se comparada à fora de TI (figura 2). 
No Amazonas, dentro e fora de TI, havia mais de uma dezena de etnias com pelo menos mil indígenas (18 e 11 etnias, respectivamente). Nas demais UFs investigadas (Mato Grosso do Sul e Rio Grande do Sul), as quantidades de etnias com mais de mil indígenas foram inferiores a cinco (5), tanto dentro quanto fora de TI. No Amazonas, apesar da maior quantidade de etnias, as frequências de indígenas em domicílios improvisados foram comparativamente menos expressivas. Dentro de TI, a maior taxa foi observada para a etnia Mura (3,2 por mil) e, fora de TI, para a Baré (11,8 por mil). No Mato Grosso do Sul e no Rio Grande do Sul, as mais elevadas taxas dentro de TI foram registradas para as etnias Guarani Kaiowá e Kaingang (2,4 e 1,2 por mil, respectivamente). Fora de TI, as cifras foram expressivamente mais elevadas (82,0 e 90,9 por mil, respectivamente).

\section{Discussão}

Nas últimas décadas, com base em recomendações internacionais, diversos países têm expandido a cobertura de seus censos demográficos de modo a incluir a produção de dados acerca de populações socioculturalmente diferenciadas presentes em seus territórios (DEL POPOLO, 2008; UN, 2009). No tocante às populações indígenas, são reconhecidos importantes desafios na captação de dados e nas formas de categorização dos diversos temas investigados pelos censos, uma vez que se observam diversificados padrôes de organização social, incluindo diferentes formas de interação com o meio ambiente e os espaços peri- e intradomiciliares (ANDERSON et al., 2016; AZEVEDO, 2011; KERTZER; AREL, 2002).

No Brasil, a investigação sobre características dos domicílios com presença indígena é um tema relativamente recente e que vem possibilitando reflexões acerca das estatísticas oficiais produzidas sobre esse segmento da população (MARINHO; SANTOS; PEREIRA, 2011; PEREIRA et al., 2009). A esse respeito, é relevante notar a maneira como os domicílios indígenas já foram descritos por agências governamentais responsáveis pela produção de estatísticas oficiais. Por exemplo, a coletânea Tipos de habitação rural no Brasil, publicada pelo IBGE na década de 1970, incluiu um capítulo intitulado "Habitação de economia primitiva - a casa do índio", no qual se indicou:

A casa do indígena é o tipo mais primitivo e rústico que se conhece no Brasil. A aldeia reúne várias famílias, formando uma taba ou maloca comunal, a qual 
varia de tamanho de acordo com o número de ocupantes. A casa é coletiva [...]. As malocas são agrupamentos de forma geralmente circular ou elíptica, em habitat concentrado, que reúnem habitações de tamanhos variáveis (COSTA; MESQUITA, 1978, p. 61).

As perspectivas explicitadas nessa passagem, marcadas por generalização e uso de conceitos como "primitivo" e "rústico", se contrapõem à descrição dos diversos modos de viver indígena presentes na literatura antropológica (GALLOIS, 2004; MELATTI, 2007; NOVAES, 1983). Entre outros aspectos, a diversidade socioantropológica dos povos indígenas se reflete nas formas como se apropriam e utilizam os espaços onde habitam. Por exemplo, no caso dos Tuyuka e alguns grupos Yanomami do noroeste amazônico, toda a comunidade se concentra numa única casa (NOVAES, 1983). Já entre povos do Brasil Central (como os Kraô, Xavante e alguns grupos xinguanos), são edificadas grandes aldeias com as habitações formando um círculo ou semicírculo, sendo o centro destinado a reuniōes e rituais (MELATTI, 2007). Os materiais utilizados na construção das casas indígenas podem ser os mais diversos, a depender do contexto sociocultural, assim como a organização dos espaços internos (NOVAES, 1983).

A captação e interpretação de estatísticas relativas à alfabetização e rendimento também se revestem de particularidades no caso de populações indígenas (GRUPIONI, 2016; MELATTI, 2007). A própria agência governamental brasileira responsável pela realização dos censos nacionais reconhece a existência de limitações nos procedimentos de obtenção de dados censitários sobre essas populações, visto que, em muitos contextos, os “processos de educação se orientam por currículos diferenciados que consideram saberes tradicionais, por vezes com uso das línguas indígenas" (IBGE, 2012, p. 70). Da mesma forma, para muitas sociedades indígenas, as atividades relacionadas a trabalho são organizadas de maneira coletiva (caçadas, pescarias, coletas, produção de alimentos etc.) e/ou não se vinculam diretamente a rendimento econômico (MELATTI, 2007).

Face a essas complexidades inerentes aos processos de classificação, a interpretação dos resultados apresentados neste trabalho deve ser cautelosa. São quantificações que requerem minuciosa contextualização com vistas a verificar, por exemplo, se o que está sendo considerado “improvisado" não faz parte do repertório de modos de construção de habitações indígenas. É necessário 
reconhecer que a ocorrência de indígenas em domicílios improvisados, tal como encontrada neste estudo, pode estar relacionada a padrões diferenciados de moradias, alocadas pelos recenseadores em categorias que remetem a uma condição de "improvisação". Infelizmente, essa é uma questão que não pode ser reavaliada a partir dos próprios dados censitários, já que o Censo 2010 não incluiu perguntas específicas sobre materiais usados na construção de moradias e outras características que poderiam ser utilizadas para se confrontar com a classificação de improvisado originalmente feita pelos recenseadores.

Ainda que problemas de classificação não possam ser descartados, as análises conduzidas neste estudo evidenciam que, em algum grau, pessoas residentes em domicílios improvisados apresentavam condição de maior vulnerabilidade socioeconômica. Nesse sentido, no tocante às comparações segundo cor ou raça, a ocorrência de domicílios improvisados cujos responsáveis eram pardos, pretos e indígenas $(2,3 ; 2,5$ e 4,0 por mil, respectivamente) foi expressivamente maior em comparação a brancos e amarelos (1,2 e 1,6 por mil, respectivamente), refletindo um padrão de desigualdade amplamente reconhecido (TELLES, 2004; SCHWARTZMAN, 2007). Além disso, a comparação entre indígenas que residiam em domicílios improvisados e permanentes mostrou que, proporcionalmente, os primeiros eram menos alfabetizados e tinham menor rendimento, tanto em áreas urbanas como nas rurais. Adicionalmente, as ocorrências de indígenas em domicílios improvisados foram mais expressivas em áreas urbanas e fora de terras indígenas. Cabe destacar que, de acordo com o Instituto Socioambiental (ISA, 2016), do total da extensão das terras indígenas no Brasil, apenas 1,6\% se situam fora da Amazônia Legal, abarcando regióes que se destacaram nos resultados deste trabalho, sobretudo aquelas mais ao sul do país (Sul e Centro Oeste).

Apesar dos desafios interpretativos impostos pelos dados censitários a respeito da classificação dos domicílios indígenas, chamam atenção os resultados encontrados para indígenas Guarani Kaiowá, cujas terras estão localizadas principalmente no Mato Grosso do Sul. Além de ser a etnia com maior taxa de indivíduos residentes em domicílios improvisados, houve uma expressiva diferença dentro e fora de terra (2,4 vs. 82,0 por mil, respectivamente). $\mathrm{Na}$ última década, o caso dos Guarani Kaiowá se tornou emblemático acerca da crítica situação de povos indígenas em regiōes do país marcadas pela expansão de 
frentes econômicas e demográficas, associando-se a consequências como elevadas taxas de desnutrição, suicídio em jovens e violência perpetrada por não indígenas (TAULI-CORPUZ, 2016; WAISELFISZ, 2014).

Se analisada a partir de uma perspectiva nacional, a ocorrência de domicílios indígenas improvisados pode parecer pouco expressiva, uma vez que corresponde a menos de $1 \%$ do total de domicílios indígenas existentes no país. Acrescido a isso, de acordo com o IBGE (2012), houve redução na proporção de domicílios com responsáveis indígenas classificados como improvisados entre 2000 e 2010, passando de 0,8\% para 0,4\% em áreas urbanas; e de 3,5\% para $0,4 \%$ nas rurais. No entanto, conforme evidenciado através dos resultados da presente investigação, diferenças expressivas surgiram ao se desagregar os dados segundo recortes de cor ou raça e, no caso dos indígenas, de acordo com etnia e localização dentro e fora de TI.

Em algumas das estratificações analisadas, como por exemplo no MS e RS, mais de 15 em cada mil indígenas residentes em domicílios fora TI moravam em domicílios improvisados. Para esse segmento, além de menos alfabetizado e com menor rendimento per capita, os procedimentos censitários não incluíram a coleta de dados sobre saneamento. É preocupante que para esses indígenas, reconhecidamente submetidos a maiores vulnerabilidades, não se disponha de informações fundamentais para caracterização da situação de saúde. Ao longo dos últimos anos, análises acerca de variados desfechos demonstram que os indígenas apresentam indicadores que apontam condições menos favoráveis em relação ao restante da população brasileira (COIMBRA et al., 2013; DIEHL, 2001; ESCOBAR et al., 2015; KÜHL et al., 2009; LEANDRO-REGUILLO et al., 2015; MARQUES et al., 2014, entre outros). No tocante à saúde de crianças indígenas, dados com representatividade nacional revelaram prevalências de desnutrição e diarreia $(25,7 \%$ e $23,6 \%$, respectivamente) bastante superiores àquelas registradas para crianças não indígenas (7,1\% e 9,4\%, respectivamente) (COIMBRA et al., 2013; ESCOBAR et al., 2015). Nesse conjunto de estudos, é recorrente o argumento de que as condições domiciliares e ambientais se relacionam de maneira muito próxima com a ocorrência desses agravos.

$\mathrm{O}$ presente estudo apresenta limitaçôes relacionadas sobretudo à fonte utilizada. Uma delas é a ausência de dados pormenorizados sobre distribuição espacial dos domicílios, para além de situação (urbano e rural) e dentro e fora de 
terra indígena. Por exemplo, seria importante buscar compreender a distribuição dos domicílios classificados como improvisados nos espaços urbanos (se em regiōes de periferia das cidades, etc.). Tampouco há informaçôes detalhadas sobre os domicílios, como área física, existência de divisões internas e tipos de materiais usados nas construções, entre outras, que poderiam contrapor-se à classificação dos domicílios disponível a partir dos dados censitários. A respeito da classificação das etnias, há tanto o uso de categorias étnicas mais específicas (como "Guarani Mbya" e "Guarani Kaiowa") como mais gerais ("Guarani”), que possivelmente se sobrepõem. Além disso, para aproximadamente 20\% dos indígenas que residiam em domicílios improvisados, foram registradas categorias como "não determinadas", "mal definidas" e "não sabem", o que pode ter levado a uma subestimativa das frequências e taxas para etnias específicas.

\section{Considerações finais}

À semelhança do ocorrido em vários países da América Latina, os censos decenais realizados no Brasil nas últimas décadas vêm ampliando a captação de dados acerca das populações indígenas (DEL POPOLO, 2008; LOVEMAN, 2014). Para essas autoras, isso se deve ao crescente reconhecimento da diversidade étnico-racial na região. Considerando que os recenseamentos visam retratar características sociodemográficas em larga escala, em geral no âmbito das populações nacionais, é imprescindível que sejam conduzidas análises que abordem criticamente os perfis que emergem para os indígenas através das quantificações populacionais (OLIVEIRA 2012; PEREIRA et al., 2009). Tal exercício é fundamental, uma vez que os dados demográficos são amplamente empregados na concepção, implementação e monitoramento de políticas públicas nas mais diversas áreas, incluindo a saúde.

Neste estudo, destacamos dados sobre indígenas derivados do Censo 2010 com foco na classificação de domicílios, em especial os denominados "domicílios improvisados". De um ponto de vista antropológico, é uma dimensão de particular relevância, pois, como detalhado ao longo do texto, ao mesmo tempo que pode decorrer de problemas de classificação, no sentido de associar (etnocentricamente) modos de habitação indígena à "improvisação", é possível que, em certos contextos, se relacionem a condições de maior vulnerabilidade socioeconômica. Ainda que no âmbito da presente investigação não tenha sido 
possível prover respostas a essas questões devido a limitações das fontes de dados, julgamos que uma contribuição importante é exercitar uma perspectiva de questionamento quanto ao emprego das categorias censitárias para povos culturalmente diferenciados, como é o caso das populações indígenas.

Se há um aspecto inquestionável no conjunto das questóes abordadas neste estudo, é quanto à necessidade de aprimorar a captação de dados sobre indígenas nas estatísticas oficiais brasileiras, o que inclui os censos demográficos. Idealmente, tal aprimoramento envolveria o delineamento de categorias mais afins à sociodiversidade indígena, o que pode se revestir de dificuldades em esforços de caracterização demográfica tão abrangentes como são os censos nacionais. Mesmo frente a esse desafio na caracterização dos domicílios, dimensão tão central para análises do processo saúde-doença, um passo importante seria ampliar o diálogo entre antropologia e demografia, tanto no estabelecimento das categorias de coleta de dados como na análise e interpretação das estatísticas censitárias. ${ }^{1}$

\section{Agradecimentos}

À Fundação Carlos Chagas Filho de Amparo à Pesquisa do Estado do Rio de Janeiro - FAPERJ (E-26/102.352/2013 - Bolsa "Cientista de Nosso Estado"). E também a James Welch e Carlos E.A. Coimbra Jr., pela leitura crítica e inúmeras sugestões editoriais.

\section{Referências}

ALVES, J.E.D.; CAVENAGHI, S. Questôes conceituais e metodológicas relativas a domicílio, família e condiçōes habitacionais. In: CONGRESSO DA ASSOCIAÇÃO LATINOAMERICANA DE POPULAÇÃO, Caxambu, 2004. Anais... Caxambu: ALAP, 2004.

ANDERSON, I.; ROBSON, B.; CONNOLLY, M. et al. Indigenous and tribal peoples' health (The Lancet-Lowitja Institute Global Collaboration): a population study. The Lancet, v. 388, n. 10040, p. 131-157, 2016.

AZEVEDO, M..M. O Censo 2010 e os povos indígenas. In: RICARDO, B.; RICARDO, F. (Org.) Povos Indigenas no Brasil: 2006-2010. São Paulo: Instituto Socioambiental, 2011. p. 45-48.

BAILIE, R.S.; STEVENS, M.; McDONALD, E.L. The impact of housing improvement and socio-environmental factors on common childhood illnesses: a cohort study in Indigenous Australian communities. J. Epidemiol. Community Health, v. 66, n. 9, p. 821-831, 2012. 
BERCOVICH, A.; PEREIRA, N.O.P. Unidad de empadronamiento: ¿hogar, vivienda o familia? Ventajas y desventajas del enfoque del censo brasileño. In: América Latina: aspectos conceptuales de los censos del 2000. Seminario Censos 2000. Parte IV. Vivienda, hogar y familia. Santiago: CEPAL/CELADE, 1999, p.171-182.

BOOTH, H. Ethnic differentials in the timing of family formation: A case study of the complex interaction between ethnicity, socioeconomic level, and marriage market pressure. Demographic Research, v. 23, p. 154-185, 2010.

COIMBRA, C.E.A; SANTOS, R.V; WELCH, J.R et al. The First National Survey of Indigenous People's Health and Nutrition in Brazil: rationale, methodology, and overview of results. BMC Public Health, v. 13, p. 13-52, 2013.

COSTA, Í.B.; MESQUITA, H.M. Tipos de habitação rural no Brasil. Rio de Janeiro: IBGE, 1978.

Del POPOLO, F. Los pueblos indígenas y afrodescendientes em las fuentes de datos: experiencias en América Latina. Santiago: CEPAL/Naciones Unidas, 2008.

DIEHL, E.E. Agravos na saúde Kaingáng (Terra Indígena Xapecó, Santa Catarina) e a estrutura dos serviços de atenção biomédica. Cad. Saúde Pública, v. 17, n. 2, p. 439-445, 2001.

ESCOBAR, A.L.; COIMBRA Jr, C.E.A; WELCH, J.R. et al. Diarrhea and health inequity among Indigenous children in Brazil: results from the First National Survey of Indigenous People's Health and Nutrition. BMC Public Health, v. 15: 191, 2015.

FUNDAÇÃO NACIONAL DO ÍNDIO/INSTITUTO BRASILEIRO DE GEOGRAFIA E ESTATÍSTICA. O Brasil indígena: resultados do Censo Demográfico 2010. Divulgação da FUNAI, 2011.

GALLOIS, C.J.S. Sentidos e formas do habitar indígena: entre mobilidade e sedentarização. Estudo de caso entre os Wajāpi do Amapá. Dissertação de Mestrado. Instituto de Pesquisa e Planejamento Urbano e Regional, Universidade Federal do Rio de Janeiro, Rio de Janeiro, 2004.

GRUPIONI, L.D.B. Educação escolar indígena. Povos Indígenas no Brasil. Instituto Socioambiental (ISA). Disponível em: https://pib.socioambiental.org/pt/c/politicasindigenistas/educacao-escolar-indigena/introducao Acesso em: 22 jun 2016.

INSTITUTO BRASILEIRO DE GEOGRAFIA E ESTATÍSTICA (IBGE). Tendências Demográficas: uma análise dos indígenas com base nos resultados da amostra dos Censos Demográficos 1991 e 2000. Rio de Janeiro: Instituto Brasileiro de Geografia e Estatística, 2005.

. Características Gerais dos Indígenas. Resultados do Universo. Censo Demográfico

2010. Rio de Janeiro: Instituto Brasileiro de Geografia e Estatística, 2012.

. Metodologia do Censo Demográfico 2010. Censo Demográfico. Rio de Janeiro:

Instituto Brasileiro de Geografia e Estatística, 2013. 
INSTITUTO SOCIOAMBIENTAL. Terras Indígenas. Localização e extensão das TIs. Povos Indígenas no Brasil. Instituto Socioambiental (ISA). Disponível em: https://pib. socioambiental.org/pt/c/terras-indigenas/demarcacoes/localizacao-e-extensao-das-tis Acesso em: 22 jun 2016.

KERTZER, D.; AREL, D. Census and Identity: The politics of race, ethnicy and language in National Censuses. Cambrige: Cambrige University Press, 2002.

KING, M.; SMITH, A.; GRACEY, M. Indigenous health part 2: the underlying causes of the health gap. The Lancet, v. 374, n. 9683, p. 76-85, 2009.

KUHL, A.M. et al. Perfil nutricional e fatores associados à ocorrência de desnutrição entre crianças indígenas Kaingáng da Terra Indígena de Mangueirinha, Paraná, Brasil. Cad. Saúde Pública, v. 25, n. 2, p. 409-420, 2009.

LEANDRO-REGUILLO, P. et al. Urban and architectural risk factors for malaria in indigenous Amazonian settlements in Brazil: a typological analysis. Malaria Journal, v. $14,2015$.

LOVEMAN, M. National Colors: racial classification and the state in Latin America. Oxford: Oxford University Press, 2014.

MARINHO, G.L; SANTOS, R.V.; PEREIRA, N.O.M. A classificação dos domicílios indígenas no censo demográfico 2000: subsídios para análise das condições de saúde. Rev. Bras. Estud. Popul., v. 28, n. 2, p. 449-466, 2011.

MARQUES, M. et al. Magnitude da tuberculose pulmonar na população fronteiriça de Mato Grosso do Sul (Brasil), Paraguai e Bolívia. Cad. de Saúde Pública, v. 30, n. 12, p. 2631-2642, 2014.

MELATTI, J.C. Indios do Brasil. São Paulo: EDUSP, 2007.

MONTENEGRO, R.A.; STEPHENS, C. Indigenous health in Latin America and the Caribbean. The Lancet, v. 367, pp.1859-1869, 2006.

NOVAES, S.C. (Org.). Habitações Indígenas. São Paulo: Nobel/ Edusp, 1983.

OLIVEIRA, J.P. Mensurando alteridades, estabelecendo direitos: práticas e saberes governamentais na criação de fronteiras étnicas. Dados, v. 55, n. 4, p. 1055- 1088, 2012.

PAGliARO, H.; AZEVEDO, M.M.; SANTOS, R.V. (Org.). Demografia dos povos indígenas no Brasil. Rio de Janeiro: Editora Fiocruz e Associação Brasileira de Estudos de População, 2005.

PEREIRA, N.O.M. et al. Demography, territory, and identity of Indigenous peoples in Brazil: The Xavante Indians and the 2000 Brazilian national census. Human Organization, v. 68 , n. 2, p.166-180, 2009.

PHIBBS, P.; THOMPSON, S. The health impacts of housing: toward a policy-relevant research agenda, AHURI Final Report No 173. Melbourne: Australian Housing and Urban Research Institute, 2011. 
SANTOS, R.V.; TEIXEIRA, P.T. O “indígena” que emerge do Censo Demográfico de 2010. Cad. de Saúde Pública, v. 27, n. 6, p. 1048-1049, 2011.

SCHWARTZMAN, L.F. Does money whiten? Intergenerational changes in racial classification in Brazil. American Sociological Review, v. 72, n. 6, p. 940-963, 2007.

STEPHENS, C. et al. Disappearing, displaced, and undervalued: a call to action for Indigenous health worldwide Indigenous health in Latin America and the Caribbean. The Lancet, v. 367, n. 9527, p.1859-1869, 2006.

TAULI-CORPUZ, V. Report of End of Mission Statement. United Nations Special Rapporteur on the rights of indigenous peoples. United Nations. Disponível em: https://nacoesunidas. org/wp-content/uploads/2016/03/SR-on-IPs-end-of-mission-statement-Brazil-17-03-2016final.pdf Acesso em: 22 jun 2016.

TELLES, E. Race in Another America: the significance of skin color in Brazil. Princeton e Oxford: Princeton University Press, 2004.

UNITED NATIONS (UN). Principles and Recommendations for Population and Housing Censuses. Revision 2, New York, 2008. . State of The World's Indigenous Peoples. New York, 2009.

WAISELFISZ, J.J. Mapa da violência 2014: Os jovens do Brasil. Secretaria de Políticas de Promoção da Igualdade Racial. Secretaria Nacional da Juventude. Brasília, 2014.

\section{Nota}

${ }^{1}$ G. L. Marinho foi responsável pela concepção da pesquisa, análise de dados e redação do artigo. A.D.R. Caldas participou da análise de dados e da redação do artigo. R.V. Santos foi responsável pela concepção da pesquisa, análise de dados e redação do artigo. 
Indigenous residents in "improvised" households according to the 2010 Brazilian National Census Brazilian national censuses classify households according to three categories: "permanent", "improvised", and "collective". This classification scheme is relevant for analysis of health profiles because detailed sanitation data are only collected for the subset of "permanent" households. Based on data from the 2010 Brazilian National Census, in this paper we investigate sociodemographic characteristics (sex, age, literacy, per capita income, and ethnic affiliation) of Indigenous persons residing in households classified as "improvised". The occurrence of indigenous residents in "improvised" households (3.3 per thousand Indigenous individuals) was twice that observed for non Indigenous persons (1.5 per thousand individuals). Indigenous persons residing in "improvised" households presented lower literacy rates and per capita income, especially in urban areas and outside Indigenous reserves. Guarani Kaiowá e Kaingang in urban areas and outside Indigenous reserves had greater proportions of individuals residing in "improvised" households (82.0 and 90.9 per thousand, respectively). While the higher frequencies of Indigenous persons living in "improvised" households may involve problems in defining and applying these categories, it is possible that Indigenous persons living in "improvised" households, especially in urban areas and outside indigenous reservations, are more socioeconomically vulnerable.

Keywords: indigenous population; censuses; social inequity. 